\title{
Pedicled Latissimus Dorsi Myocutaneous Flap Transthoracic Transposition for Repairing Neck and Shoulder Soft Tissue Defect Combined with Infection
}

\author{
Abulaiti Abula \\ the First Affiliated Hospital of Xinjiang Medical University \\ Yanshi Liu \\ the First Affiliated Hospital of Xinjiang Medical University \\ Feiyu Cai \\ the First Affiliated Hospital of Xinjiang Medical University \\ Kai Liu \\ the First Affiliated Hospital of Xinjiang Medical University \\ Peng Ren \\ the First Affiliated Hospital of Xinjiang Medical University \\ Alimujiang Abulaiti \\ the First Affiliated Hospital of Xinjiang Medical University \\ Xiayimaierdan Maimaiti \\ the First Affiliated Hospital of Xinjiang Medical University \\ Aihemaitijiang Yusufu ( $\nabla$ ahmatjang@163.com ) \\ the First Affiliated Hospital of Xinjiang Medical University
}

\section{Research Article}

Keywords: Latissimus dorsi musculocutaneous flap, Skin flap, Soft tissue defect, Soft tissue infection

Posted Date: May 26th, 2021

DOI: https://doi.org/10.21203/rs.3.rs-526488/v1

License: (c) (i) This work is licensed under a Creative Commons Attribution 4.0 International License. Read Full License 


\section{Abstract}

Background: To explore the clinical application and selection of latissimus dorsi myocutaneous flap in repairing neck and shoulder soft tissue defect combined with infection.

Methods: From July 2017 to December 2019, 11 patients with neck and shoulder soft tissue defect combined with infection in our hospital were repaired by the pedicled latissimus dorsi myocutaneous flap (PLDMF) according to the shape and size of the soft tissue defects, including 9 males and 2 females, with an average age of $40.2 \pm 12.6$ years. The average defect area after debridement of infected and necrotic tissue was $(7.0 \pm 1.3) \mathrm{cm} \times(4.8 \pm 1.2) \mathrm{cm}$, and the average area of the flaps was $(34.4 \pm 3.8) \mathrm{cm} \times$ $(6.0 \pm 1.0) \mathrm{cm}$. The donor site was sutured directly.

Results: Seven cases of skin flaps healed by the first intention, while 4 cases developed infections at the distal ends of the skin flaps after surgery, which all survived after anti-infection treatment and repeated dressing changes for infection control, and the donor and recipient sites of the flaps healed well. Followed up for an average of $17.3 \pm 3.8$ months with good flap blood supply and limb function, there was no recurrence of infection.

Conclusions: PLDMF is an idea for repairing neck and shoulder soft tissue defect combined with infection, with high survival rate, low postoperative infection recurrence rate, and good functional repair ability, leading to good clinical application value. However, surgical indications should be strictly carried out due to the inferior aesthetic of flaps.

\section{Background}

Latissimus dorsi myocutaneous flap has been widely used in the repair of adjacent soft tissue defects due to the advantages of large flap area and carrying muscles ${ }^{1,2}$. However, with the development of microsurgery technology, the dorsal thoracic artery perforator flap without latissimus dorsi has achieved better soft tissue repair effects due to its thinner cut and less damaged to the donor site ${ }^{3,4}$. In contrast, although the traditional latissimus dorsi myocutaneous flap in the repair of soft tissue defects caused more trauma and inferior aesthetic, it still has a relatively reliable repair effect in repairing wounds with soft tissue infections, such as when it is necessary to expand the debridement of infection and necrotic tissue ${ }^{5,6}$. The purpose of this study is to further clarify the clinical application value of this flap by analyzing the latissimus dorsi musculocutaneous flap to repair infectious soft tissue defects in the shoulder and neck. This study reported 11 patients with large neck and shoulder soft tissue defects combined with infection. After extensive debridement, the latissimus dorsi myocutaneous flap was applied to cover the soft tissue defect to observe the repair effect of this flap in similar injuries.

\section{Methods}

A total of 11 patients with neck and shoulder soft tissue defect combined with infection who were admitted to the Department of Microsurgical Repair at the Orthopedic Center of the First Affiliated 
Hospital of Xinjiang Medical University from July 2017 to December 2019 were included in this study, including 9 males and 2 females, with an average age of $40.2 \pm 12.6$ years. The causes of injuries were traffic accident injury in 8 cases, heavy object crush injury in 2 cases, and shoulder tumor resection in 1 case. After debridement of infected and necrotic tissue, the average defect area was $(7.0 \pm 1.3) \mathrm{cm} \times$ $(4.8 \pm 1.2) \mathrm{cm}$. According to the shape and size of the soft tissue defect, PLDMF was used to repair the soft tissue defect, and the average area of the flap was $(34.4 \pm 3.8) \mathrm{cm} \times(6.0 \pm 1.0) \mathrm{cm}$. The donor site was sutured directly.

The inclusion criterion was the soft tissue defects of neck and shoulder caused by local debridement or tumor resection, which could not be sutured directly. The exclusion criteria were as follows: a. Patients with serious underlying diseases, such as severe heart failure, renal failure, severe hypertension, and diabetes, who could not tolerate long-term surgery; $b$. Patients with severe infection on the wound surface of the recipient site, without performing thorough debridement and good control of infection; c. Patients with severe extremities vascular sclerosis, which can lead to flap vascular crisis, and thereby seriously affecting the postoperative effect.

\section{Surgical technique}

Under general anesthesia, the patient took a left lateral decubitus position with the right upper limb flexed on the front chest. Before flap design, ultrasound Doppler was used to explore the perforator branches of the dorsal thoracic artery at the intersection of $6-8 \mathrm{~cm}$ below the axillary apex and the dorsal thoracic artery. When designing the flap, point A was marked at the apex of the posterior axillary wall, point $B$ was marked at the right posterior superior iliac spine, and the line between point $A$ and point $B$ was the axis of the latissimus dorsi myocutaneous flap. According to the marked points, lines, and planes, the designed size of skin flaps were $38 \mathrm{~cm} \times 6 \mathrm{~cm}$ and $40 \mathrm{~cm} \times 8 \mathrm{~cm}$, respectively.

With the aid of a head-mounted magnifying glass, cut open the frontal edge skin, subcutaneous tissue, and fascia of the designed flap to fully expose the leading edge of the latissimus dorsi, along which the latissimus dorsi was freed and lifted up. Then cut open the posterior edge skin, subcutaneous tissue and fascia of the designed flap, the latissimus dorsi myocutaneous flap was cut off from the distal end of the designed flap, the free latissimus dorsi myocutaneous flap was dissected from the distal end to the proximal end, and then carefully stop bleeding in the wound (Figure 1). At 6-8cm in the axilla, thoracodorsal arteries and veins, and thoracodorsal nerves were seen into the designed myocutaneous flap. Free the myocutaneous flap to the axilla as the rotation point, where the fascia was loosened and the possible compression caused by the rotation of the myocutaneous flap was relieved, the myocutaneous flap was then protected after being wrapped with wet gauze. Full-thickness suture was performed in the donor site of the myocutaneous flap, a rubber tissue was used for drainage, and a sterile dressing was applied.

The patient's position was changed from side lying to supine, with the back of the affected side hand abducted. Firstly, the surface inflammatory granulation, inactivated and necrotic tissue were removed 
along the wound edge of neck, shoulder and back, and the branches of cephalic vein and external jugular vein were explored and ligated. Then the wound was rinsed repeatedly with hydrogen peroxide and normal saline to provide a good recipient site for the skin flap. Meanwhile, carefully observe the blood supply of the latissimus dorsi myocutaneous flap, cut open the skin and subcutaneous tissue of the axilla and chest, the flap was transferred to cover the wound through the open channel. Then the latissimus dorsi muscle tissue and the soft tissue inside the wound surface were sutured and fixed, thereafter the skin around the flap was sutured. There should be no local tension after the flap was sutured and covered, and the wound surface should be well covered. Rubber tissue was placed around the flap for drainage.

\section{Results}

Seven cases of skin flaps healed by the first intention, while 4 cases developed infections at the distal ends of the skin flaps after surgery, which all survived after anti-infection treatment and repeated dressing changes for infection control, and the donor and recipient sites of the flaps healed well. All patients were followed up for an average of $17.3 \pm 3.8$ months with good flap blood supply and limb function, and there was no recurrence of infection.

\section{Typical case}

A 22-year-old male patient suffered an open fracture of the right clavicle combined with skin and soft tissue defects from a car accident. Debridement treatment was given at the first intention, and then skin flap transplantation was performed after the wound infection was controlled and the granulation tissue was well formed. In the second stage, after the removal of excess inflammatory granulation, infection, and necrosis tissue of the wound, the area of the soft tissue defect was measured to be $8 \mathrm{~cm} \times 6 \mathrm{~cm}$, and the fractured end of clavicle and subclavian vascular pulsation could be seen in the wound. The PLDMF was designed based on the soft tissue defect, and clavicle fracture reduction and internal fixation were performed at the same time. After 8 months of follow-up, the flaps healed well without recurrence of infection, and the fracture was well fixed (Figure 2-3).

\section{Discussion}

The latissimus dorsi myocutaneous flap is one of the largest skin flaps that can be cut in the human body, and can be designed to cut various types of skin flaps, muscle flaps, myocutaneous flaps, lobed myocutaneous flaps and composite myocutaneous flaps accoring to the characteristics of soft tissue defects ${ }^{7}$. In 1976, Baudet et al. reported the successful case of free latissimus dorsi flap for the first time, making the application of this flap in wound surface repair gradually widespread ${ }^{3}$. Large-area soft tissue defects caused by severe neck and shoulder trauma or tumor resection often have large volume defects, especially in the case of exposed joint, the application of simple free skin flap to cover soft tissue defects is often difficult to meet the requirements for joint function protection and wound healing ${ }^{8,9}$. In contrast, 
the latissimus dorsi myocutaneous flap can not only meet the needs of soft tissue filling in the neck and shoulders, which has a good protective effect on the shoulder joint, but also the flap is close to the neck and shoulders, and can be cut with a pedicle to cover soft tissue defects, making the blood supply of the skin flap possible and the survival rate high ${ }^{10}$. Two patients in this study suffered blood vessels, nerves and bones exposure with severe soft tissue infection. The use of a pedicled skin flap with latissimus dorsi to cover the soft tissue defect after debridement combined with internal fixation of clavicle fracture, exhibited good anti-infection ability ${ }^{11}$. Compared with free skin flap, this skin flap can provide higher antiinfection ability and flap blood supply to prevent the occurrence of skin flap necrosis, recurrence of infection and exposure of steel plate, etc. Moreover, vascular anastomosis under the microscope is not required for this skin flap, and the requirements for the surgeon's personal ability and local medical conditions are relatively low ${ }^{12}$. In this study, 1 case of clavicle fracture used atissimus dorsi myocutaneous flap to cover after fixation with internal fixation plate. Follow-up observation after surgery showed that both the skin flap and the fracture achieved good repair effect.

However, there are still some limitations for PLDMF in repairing soft tissue injury of neck and shoulder. The main blood supply artery of the atissimus dorsi myocutaneous flap comes from the dorsal thoracic artery (the subscapular artery originates about $3.0 \mathrm{~cm}$ below the axillary artery), and the dorsal thoracic artery usually gives off the medial and lateral branches. Based on the anatomical characteristics of the latissimus dorsi flap, the length of the vascular pedicle of this flap from which the dorsal thoracic artery and its medial and lateral branches can be freed is about 5.0-8.0 cm, thus there is a certain range limit for pedicled transfer ${ }^{13,14}$. Furthermore, perforating cutaneous vessel branches of the dorsal thoracic artery are small, which makes the surgery difficult to cut the free skin flap for transplantation, and the incidence of postoperative vascular crisis is high ${ }^{15,16}$. Although the PLDMF can meet the requirements for the repair distance of the soft tissue defect of the shoulder and the survival rate of the flap, the scar is located on the shoulder after the skin flap grafting, which is easy to cause friction and has a certain influence on dressing, especially for female patients who feel discomfort when wearing a bra, and the aesthetic outcome is poor.

\section{Conclusion}

The use of the PLDMF to repair large areas of soft tissue defects in the neck and shoulder combined with infection can provide better joint protection to the shoulder joints, and has very good anti-infection ability. And also, it is very easy to harvest the flap, and the survival rate is high. However, the cut distance of this flap is relatively short. When designing the flap, the distance and range of the soft tissue defect should be measured in detail to avoid the occurrence of changing the surgical plan after the operation. Moreover, the aesthetic outcome of this flap transposition is poor and has a certain impact on dressing, therefore, it should be avoided for young female patients.

\section{Abbreviations}




\section{Declarations}

\section{Ethics approval and consent to participate}

All methods in this study were carried out in accordance with the Declaration of Helsinki. This study was approved by the Ethics Committee of The First Affiliated Hospital of Xinjiang Medical University. Written informed consent was obtained from all patients for their data to be recorded in our study.

\section{Consent for publication}

Informed consent was obtained from all patients for their data to be published in our study.

\section{Availability of data and materials}

The datasets generated and analysed during the current study are not publicly available due to limitations of ethical approval involving the patient data and anonymity but are available from the corresponding author on reasonable request.

\section{Competing interests}

The authors declare that they have no competing interests.

\section{Funding}

This study was funded by the grants from National Natural Science Foundation of China (No. 82060401). The funding body was involved in the collection, analysis, and interpretation of data by supporting with salary for the time needed. They were not involved in the design or writing the manuscript.

\section{Authors' Contributions}

AA: Conducted the study. Collected, analyzed and interpreted the data. Wrote the manuscript.

YSL: Collected, interpreted and analyzed the data. Edited the manuscript.

FYC: Created and statistical analyzed the data. Edited the manuscript.

KL: Provided software assistance. Edited the manuscript. 
PR: Conducted the study and provided the data.

AA: Conducted the study and provided the data.

XM: Conducted the study and provided the data.

AY: Planned the project. Reviewed the manuscript.

Abulaiti Abula and Yanshi Liu contributed equally to this study.

All authors read and approved the final manuscript.

\section{Acknowledgements}

Not applicable

\section{References}

1. Naalla R, Bhattacharyya S, Saha S, Chauhan S, Singhal M. Versatility of the Pedicled Latissimus Dorsi Myocutaneous Flap in Reconstruction of Upper Limb and Trunk Soft Tissue Defects. J Hand Microsurg 2020;12:168-76.

2. Tashiro K, Arikawa M, Fukunaga Y, Nakatani F, Kobayashi E, Kawai A, et al. Free latissimus dorsi musculocutaneous flap for external hemipelvectomy reconstruction. MICROSURG 2019;39:138-43.

3. Ma C, Tao R, Shu J, Lei YH, Han Y. [Methods of repairing large soft tissue defect with latissimus dorsi myocutaneous flap and management of secondary wound in donor site]. Zhonghua Shao Shang Za Zhi 2020;36:1199-203.

4. Wang Y, Ren Z, Xue J, Guo L, Gao D, Hao Q, et al. [Effectiveness of posterior intercostal artery perforator flap in repair of donor defect after latissimus dorsi myocutaneous flap transfer]. Zhongguo Xiu Fu Chong Jian Wai Ke Za Zhi 2018;32:1187-91.

5. Katre MI, Keche P, Dhanajakar P. Use of Latissimus Dorsi Myocutaneous Island Flap for Pharyngeal Reconstruction in Setting of Postoperative Wound Infection in Salvage Laryngectomy. Indian J Surg Oncol 2020;11:44-6.

6. Kang SH, Kim YC, Sur YJ. Reverse turnover pedicled latissimus dorsi muscle flap for lower back reconstruction: Two case reports. Medicine (Baltimore) 2018;97:e13851.

7. Ram R, Gardner J, Alapati S, Jambhekar K, Pandey T, Montgomery C, et al. Malignant Triton Tumor (Malignant Peripheral Nerve Sheath Tumor With Rhabdomyoblastic Differentiation) Occurring in a Vascularized Free Flap Reconstruction Graft. INT J SURG PATHOL 2017;25:462-7.

8. Huang YC, Lee YY, Tso HH, Chen PC, Chen YC, Chien CY, et al. The Sonography and Physical Findings on Shoulder after Selective Neck Dissection in Patients with Head and Neck Cancer: A Pilot Study. BIOMED RES INT 2019;2019:2528492. 
9. Yang SF, Wang CM, Liu LC, Xu KY, Xiao SP, Mei J, et al. [Clinical effects of expanded super-thin perforator flaps in the shoulder, neck, and chest in reconstruction of extensive burn scars in the face]. Zhonghua Shao Shang Za Zhi 2019;35:661-7.

10. Yang LC, Wang XC, Bentz ML, Fang BR, Xiong X, Li XF, et al. Clinical application of the thoracodorsal artery perforator flaps. J Plast Reconstr Aesthet Surg 2013;66:193-200.

11. Pang $X$, Cao Z, Wu P, Tang J, Zhou Z, Yu F, et al. Outcomes of free anterolateral thigh perforator flaps versus free modified latissimus dorsi myocutaneous flaps for Gustilo type IIIB open tibial fractures with necrosis and infection. AM J TRANSL RES 2020;12:5836-43.

12. Chakrabarti S, Panuganti A, Gupta M, Ghosh A, Bhukar S, Choubey T, et al. Pedicled Latissimus Dorsi Myocutaneous Flap-an Effective Reconstructive Option for Extensive Buccal Cancer Resection in Resource Constrained and Salvage Settings. Indian J Surg Oncol 2020;11:462-8.

13. Tilgner A, Herrberger U, Oswald P. Myocutaneous flap models in the rat. Anatomy, histology and operative technique of the latissimus dorsi myocutaneous flap. Z Versuchstierkd 1988;31:225-32.

14. Kang CM, Shim JS. Volume Change of Pedicled Latissimus Dorsi Muscle Flap after Partial Breast Reconstruction. J RECONSTR MICROSURG 2018;34:651-7.

15. Claes KE, Roche NA, Opsomer D, De Wolf EJ, Sommeling CE, Van Landuyt K. Free flaps for lower limb soft tissue reconstruction in children: Systematic review. J Plast Reconstr Aesthet Surg 2019;72:71128.

16. Asaad M, Rajesh A, Wahood W, Vyas KS, Houdek MT, Rose PS, et al. Flap reconstruction for sacrectomy defects: A systematic review and meta-analysis. J Plast Reconstr Aesthet Surg 2020;73:255-68.

\section{Figures}
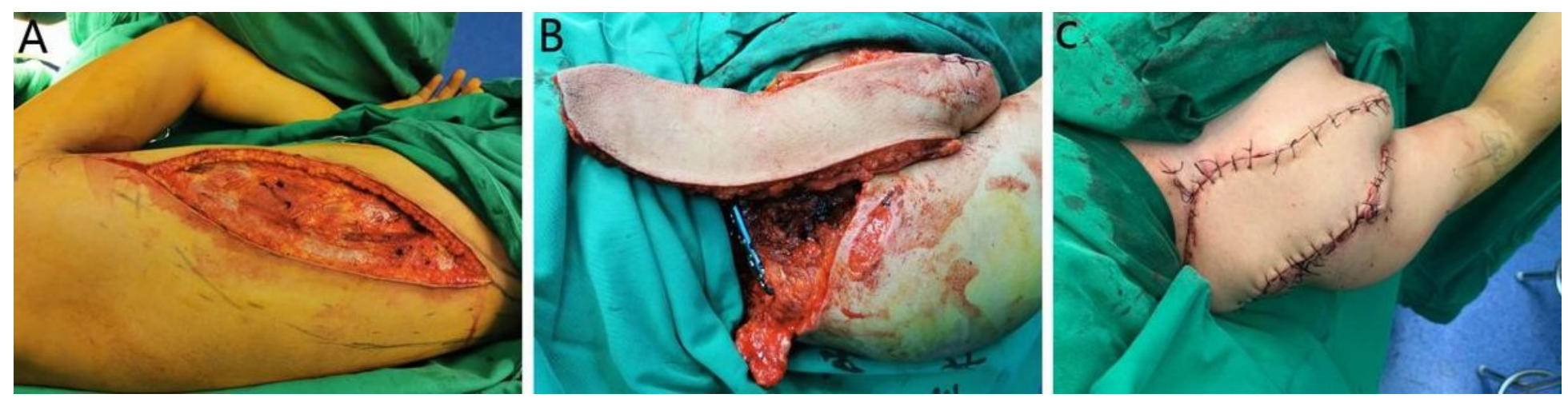

\section{Figure 1}

a Flap design and incision. b Latissimus dorsi flap inverted to cover the soft tissue defect of the shoulder. c Appearance after the skin flap transplantation. 

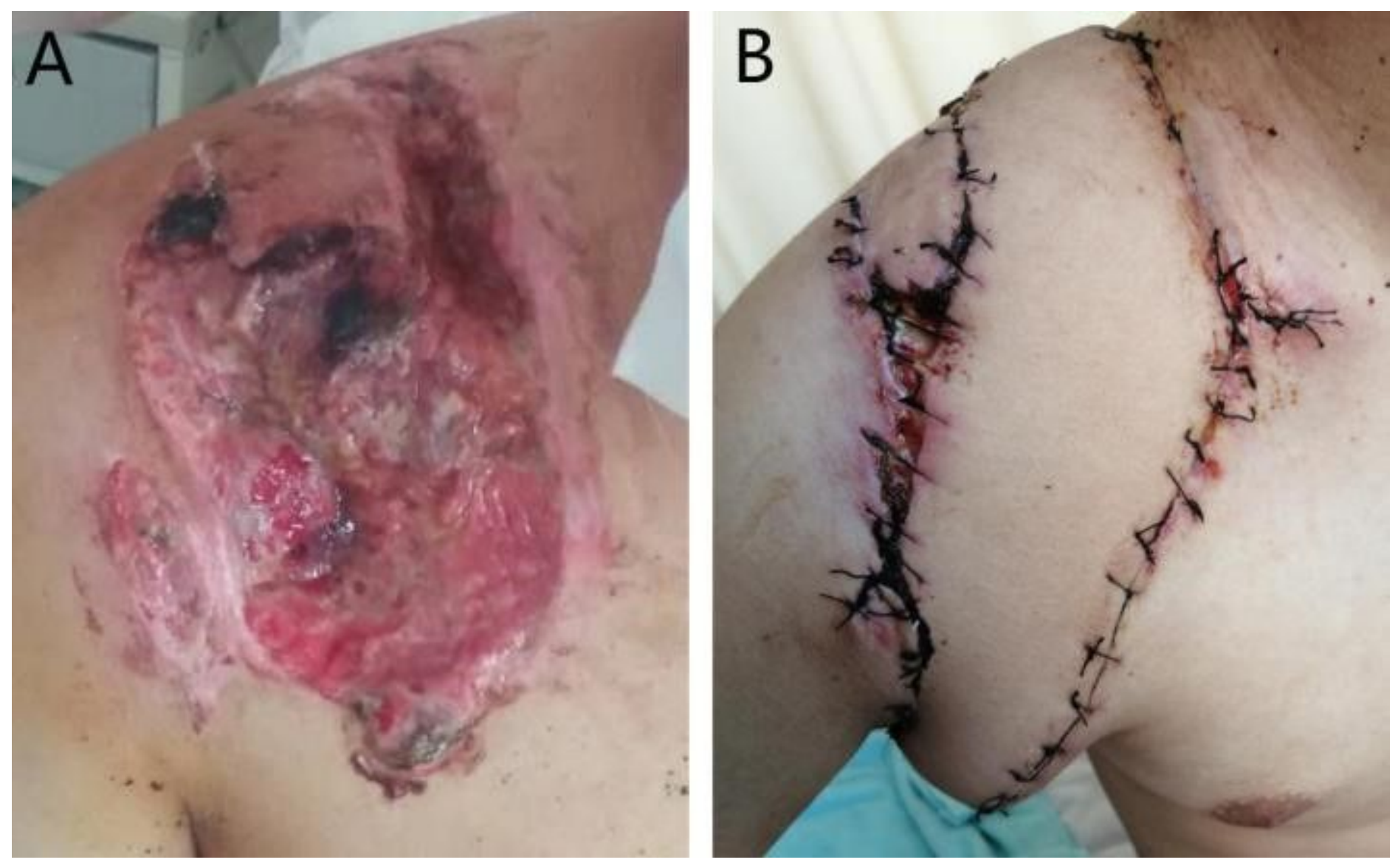

Figure 2

a soft tissue defect of the shoulder before surgery. b appearance of the skin flap one week after surgery.
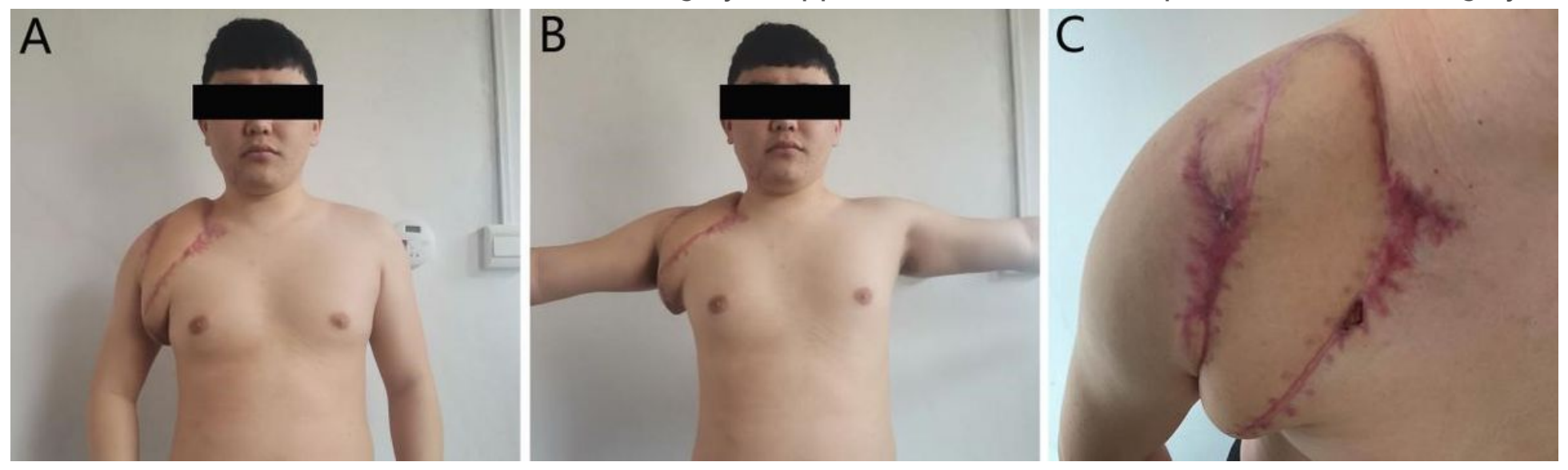

Figure 3

Appearance of the skin flap after 8 months follow-up. a standing position. b shoulder abduction position. c local appearance. 